\title{
Discrete Regions of the Sensor Protein VirA Determine the Strain-Specific Ability of Agrobacterium to Agroinfect Maize
}

\author{
J. D. Heath, ${ }^{1}$ M. I. Boulton, ${ }^{2}$ D. M. Raineri, ${ }^{1}$ S. L. Doty, ${ }^{1}$ A. R. Mushegian, ${ }^{1}$ T. C. Charles, ${ }^{1}$ J. W. Davies, ${ }^{2}$ \\ and E. W. Nester ${ }^{1}$ \\ ${ }^{1}$ University of Washington, Department of Microbiology, Box 357242, Seattle 98195-7242 U.S.A.; ${ }^{2}$ John \\ Innes Centre, Colney Lane, Norwich NR4 7UH, U.K. \\ Received 2 October 1996. Accepted 6 December 1996.
}

\begin{abstract}
The ability of Agrobacterium strains to infect transformation-recalcitrant maize plants has been shown to be determined mainly by the virA locus, implicating vir gene induction as the major factor influencing maize infection. In this report, we further explore the roles of vir inductionassociated bacterial factors in maize infection using the technique of agroinfection. The $\mathrm{Ti}$ plasmid and virA source are shown to be important in determining the ability of a strain to infect maize, and the monosaccharide binding protein $\mathrm{ChvE}$ is absolutely required for maize agroinfection. The linker domain of VirA $\mathrm{A}_{\mathrm{C58}}$ from an agroinfection-competent strain, $\mathrm{C} 58$, is sufficient to convert $\operatorname{Vir} A_{A 6}$ of a nonagroinfecting strain, A348, to agroinfection competence. The periplasmic domain of $\operatorname{Vir} A_{C 58}$ is also able to confer a moderate level of agroinfection competence to $\operatorname{Vir} A_{A 6}$. In addition, the $\operatorname{Vir} A_{A 6}$ protein from A348 is agroinfection competent when removed from its cognate $\mathrm{Ti}$ plasmid background and placed in a pTiC58 background. The presence of a pTiA6-encoded, $\operatorname{Vir} \mathrm{A}_{\mathrm{A6}^{-}}$ specific inhibitor is hypothesized and examined.
\end{abstract}

Additional keywords: host range, plant transformation, twocomponent system.

Agrobacterium is the causal agent of the plant disease crown gall. The mechanism by which Agrobacterium causes tumors on plants has been studied and described in great detail (Hooykaas and Beijersbergen 1994; Kado 1991; Zambryski 1992). Briefly, in response to signal compounds present in a

Corresponding author: E. W. Nester; phone (206) 543-0255;

fax (206) 543-8297; E-mail: gnester@u.washington.edu

Present address of D. M. Raineri: University of Illinois, Department of Microbiology, Urbana 61801 U.S.A.

Present address of S. L. Doty: University of Washington, Department of Biochemistry, Seattle 98195 U.S.A.

Present address of A. R. Mushegian: National Center for Biotechnology Information, National Library of Medicine, National Institutes of Health, Bethesda MD 20894 U.S.A.

Present address of T. C. Charles: McGill University, Department of Natural Resource Sciences, Ste-Anne-de-Bellevue, Quebec, Canada H9X 3V9. plant wound site, the bacterium induces the expression of a set of virulence (vir) genes via the VirA/VirG two-component signal transduction system (Heath et al. 1995). vir gene products excise and transfer a piece of the bacterial Ti plasmid DNA (T-DNA) into a susceptible plant cell, where it is targeted to the nucleus and integrated into the plant genome. The T-DNA encodes genes that, when expressed in the plant cell, direct the synthesis of plant growth regulators, resulting in neoplastic growth of the infected cells. In addition, the T-DNA encodes genes for the synthesis of compounds, termed opines, which the infecting bacterium can utilize as carbon and nitrogen sources. This singular ability of Agrobacterium to transform a wide variety of plants with high efficiency has become a cornerstone of genetic manipulation of plants for both commercial and scientific purposes.

Major exceptions to the natural broad host range of Agrobacterium are the plants in the family Graminae (Chilton 1993). This group of monocotyledenous grasses, which includes the economically important crop plants maize, wheat, and rice, has proven to be difficult to routinely transform by Agrobacterium-mediated methods. Recently, however, rice and maize have been transformed by using superior binary vectors and cocultivation conditions that include vir gene inducers (Hiei et al. 1994; Ishida et al. 1996). In earlier attempts to identify the barrier to transformation of maize, investigators using the method of agroinfection (Grimsley et al. 1986, 1987) demonstrated that certain Agrobacterium strains could transfer T-DNA into maize plants, although tumors were not formed. Agroinfection is an extremely sensitive assay for T-DNA transfer. Any successful transfer event has the potential to be amplified exponentially by replication of the transferred viral genome resident on the T-DNA and systemic spread of the virus. Additionally, agroinfection measures T-DNA transfer independently of T-DNA integration or expression. Therefore, investigators are able to use agroinfection to study T-DNA transfer into the transformation-resistant members of Graminae.

Boulton et al. (1989) showed that the ability of certain Agrobacterium strains to agroinfect maize is determined by the opine-utilization profile of the bacterium, which is in turn determined by factors resident on the Ti plasmid. Specifically, most Agrobacterium strains that utilize octopine and cucumopine are unable to infect maize, while those that utilize 
nopaline, agropine, and mannopine can. That study was followed by studies that determined that virA from C58, an agroinfection-competent strain, was sufficient to confer agroinfection competence on a nonagroinfecting strain, A348 (Raineri et al. 1993). In addition, Hansen et al. (1994) demonstrated that constitutive expression of the vir genes was sufficient to convert A348 to agroinfection competence. These results emphasized the importance of vir gene induction in determining the ability of certain strains to infect maize.

The relationship between vir gene induction and host range has long been recognized. One example is the limited host range of $A$. vitis strain Ag162. The vir genes of this strain are not induced by acetosyringone, the prototypical vir-inducing phenolic compound, and this strain exhibits a very limited host range of plant cell transformation. Additionally, mutant derivatives of Agrobacterium that lack the $c h v E$ gene product, which is required for monosaccharide-enhanced induction of vir expression (Cangelosi et al. 1990), exhibit a reduced host range compared with wild-type strains (Garfinkel and Nester 1980; Huang et al. 1990). Recently, an Agrobacterium strain isolated from the soil of South Korea has been shown to possess a vastly different phenolic-recognition profile compared with the extensively studied strains C58 and A6 (Lee et al. 1995). This strain also has an altered host range with respect to $\mathrm{C} 58$ and $\mathrm{A} 6$, which correlates with its altered phenolic-recognition properties. In this study, we analyze the bacterial factors important in vir gene induction, focusing on the sensor protein VirA and exploring further its role in maize agroinfection.

\section{RESULTS AND DISCUSSION}

$\operatorname{Vir} A_{A 6}$ is competent for maize agroinfection in a pTiC58 background but not in a pTiA6 background.

It has been shown that the strain-specific ability of Agrobacterium to infect maize is largely determined by the virA locus (Raineri et al. 1993). A clone harboring virA from the nopaline-type $\mathrm{Ti}$ plasmid pTiC58 was shown to restore agroinfection ability to the octopine-type strain A348 harboring a virA mutation (Raineri et al. 1993). Subsequently, we made the unexpected observation that a virA clone from the octopine-type Ti plasmid pTiA6 was able to restore agroinfection in a $\mathrm{C} 58$ strain harboring a deletion of the $\mathrm{C} 58$ virA gene (At13000) (Table 1). The same virA $A_{\mathrm{A} 6}$ clone was unable to restore agroinfection by At11068, thereby excluding copy number of the complementing virA clone as an explanation. Therefore, $\operatorname{Vir}_{\mathrm{A} 6}$ is fully functional for maize agroinfection in a pTiC58 background but not in a pTiA6 background. However, Vir $\mathrm{A}_{\mathrm{C} 58}$ is fully functional in either background. These observations suggest that pTiA6 encodes a factor that limits or inhibits the activity of $\operatorname{VirA}_{\mathrm{A} 6}$ but not of $\operatorname{VirA}_{\mathrm{C} 58}$ in agroinfection of maize. To determine whether the pTiA6-encoded "inhibitory" activity could be overcome by overexpressing Vir $_{\mathrm{A} 6}$ prior to inoculating the maize plants, we placed the $v i r A_{\mathrm{A} 6}$ coding sequence under the control of an inducible lac promoter. This clone restored agroinfection of maize in octopine-type strain $\mathrm{A} 1030$ when $\mathrm{P}_{\text {lac }}-v i r A_{\mathrm{A} 6}$ expression was preinduced by treatment with $1 \mathrm{mM}$ IPTG (isopropyl- $\beta-\mathrm{D}-$ thiogalactopyranoside) (Table 1). This result suggests that the VirA $_{A 6}$-specific inhibitor encoded by pTiA6 is limiting and can be overcome by overexpression of $\mathrm{VirA}_{\mathrm{A} 6}$. These data cannot be explained by invoking a superior interaction of VirA $_{\mathrm{A} 6}$ with $\mathrm{VirG}_{\mathrm{C} 58}$, since it was previously reported that a $\operatorname{vir} G_{\mathrm{C} 58}$ clone cannot complement a $\operatorname{vir} G_{\mathrm{A} 6}$ mutant strain for agroinfection (Raineri et al. 1993). The explanation most consistent with the data is that pTiA6 encodes an inhibitor specific for $\operatorname{Vir}_{\mathrm{A} 6}$ that restricts its ability to induce the vir genes in a maize-wound environment.

We attempted to identify the gene or genes encoding the Vir $_{\mathrm{A} 6}$-specific inhibitory activity by testing the maize agroinfection ability of a $\operatorname{vir} A_{\mathrm{A} 6}$-containing derivative of At13000 $(\mathrm{C} 58 / \mathrm{pTiC} 58 \Delta$ virA:: $\Omega$ ) complemented with an ordered set of cosmid clones made from pTiA6 (data not shown). No $\operatorname{VirA}_{\mathrm{A} 6}$-specific inhibition by a series of clones covering nearly the entire pTiA6 plasmid was observed. The only region that could not be tested was that immediately surrounding the pTiA6 origin of replication because of incompatibility with the pTiC58 origin.

\section{A discrete region of VirA is responsible for the strain specificity of maize agroinfection.}

Since the virA locus is the determining factor in conferring maize agroinfection ability, we set out to determine what part of VirA $\mathrm{C} 58_{3}$ is responsible for maize infection. It has been suggested that the sensor components of two-component signal transduction systems are modular and composed of domains that perform independent functions, which when combined in one molecule result in the desired function (Parkinson and Kofoid 1992). These domains are broadly defined as input, kinase, and receiver. The input domain of the VirA sensor molecule can be further subdivided into a periplasmic domain that interacts with ChvE (Cangelosi et al. 1990; Shimoda et al. 1993) and a linker domain that may be responsible for sensing phenolic compounds (Chang and

Table 1. Determination of ability to agroinfect maize by virA and Ti plasmid source

\begin{tabular}{|c|c|c|c|c|c|c|}
\hline \multicolumn{4}{|c|}{ Agrobacterium genotype } & \multirow[b]{2}{*}{ virA clone } & \multirow{2}{*}{$\begin{array}{l}\text { Inducing } \\
\text { condition }\end{array}$} & \multirow{2}{*}{$\begin{array}{c}\text { Maize } \\
\text { infected } \\
(\%)\end{array}$} \\
\hline Strain name & Chromosome & Ti plasmid & Source & & & \\
\hline At11068 & $\mathrm{C} 58$ & pTiA6 $\Delta v i r A:: \Omega$ & This work & $\operatorname{vir} A_{\mathrm{C} 58}$ & $\ldots$ & 88 \\
\hline At11068 & $\mathrm{C} 58$ & pTiA6 $\Delta v i r A:: \Omega$ & This work & $\operatorname{vir} A_{\mathrm{A} 6}$ & $\ldots$ & 5 \\
\hline At13000 & C58 & pTiC58 $\Delta$ virA $:: \Omega$ & Doty et al. 1996 & $v i r A_{C 58}$ & $\ldots$ & 100 \\
\hline At13000 & $\mathrm{C} 58$ & pTiC58 $\Delta v i r A:: \Omega$ & & $v i r A_{\mathrm{A} 6}$ & $\ldots$ & 100 \\
\hline A1030 & $\mathrm{C} 58$ & $\mathrm{pTiB}_{6} 806$ virA::Tn5 & Garfinkel and Nester 1980 & $\mathrm{P}_{\mathrm{lac}}-$ virA $_{\mathrm{A} 6}$ & & 2 \\
\hline A1030 & C58 & $\mathrm{pTiB}_{6} 806$ virA::Tn5 & & $\mathrm{P}_{\mathrm{lac}}-v i r A_{\mathrm{A} 6}$ & $1 \mathrm{mM} \mathrm{IPTG}^{\mathrm{a}}$ & 46 \\
\hline $\mathrm{C} 58$ & C58 & pTiC58 & Hamilton and Fall 1971 & $\ldots$ & $\ldots$ & 100 \\
\hline At11054 & C58 chvE::Tn5 & pTiC58 & Charles et al. 1994 & $\ldots$ & $\ldots$ & 0 \\
\hline
\end{tabular}

${ }^{a}$ Isopropyl- $\beta$-D-thiogalactopyranoside. 
Winans 1992; Doty et al. 1996). A series of chimeric VirA proteins composed of both $\operatorname{VirA}_{\mathrm{C} 58}$ and $\mathrm{VirA}_{\mathrm{A} 6}$ were tested for their ability to restore maize agroinfection in an At11068 $(\mathrm{C} 58 / \mathrm{pTiA} 6 \Delta v i r A:: \Omega)$ background. These hybrid proteins are represented in Figure 1 along with their corresponding maize agroinfection frequencies. Replacement of either the VirA $\mathrm{C}_{\mathrm{C} 5}$ periplasmic domain or a region composed largely of the linker domain with the corresponding region of $\operatorname{VirA}_{\mathrm{A} 6}(\mathrm{pJD} 105 \mathrm{~W}$ and pJD129W, respectively) resulted in reduced maize agro-

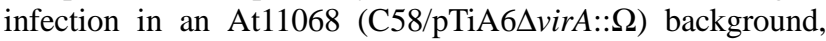
although these were not reduced to the level of wild-type $\operatorname{VirA}_{\mathrm{A6}}$. The reverse hybrids (pJD113W and pJD132W) exhibited an increase in agroinfection frequency; pJD132W restored maize agroinfection to wild-type $\operatorname{VirA}_{\mathrm{C} 58}$ levels. Chimeric VirA molecules composed of mainly $\operatorname{VirA}_{\mathrm{C} 58}$ with residues 525 to 830 from $\operatorname{VirA}_{\mathrm{A} 6}$ (the $\mathrm{C}$-terminal half of the kinase domain and receiver domain) or the promoter and residues 1 to 63 from $\operatorname{VirA}_{\mathrm{A} 6}$ (the N-terminal and first transmembrane domain) exhibited agroinfection frequencies similar to that of wild-type $\operatorname{VirA}_{\mathrm{C} 58}$ (data not shown). These results indicate that a region composed of the C-terminal 20 amino acids of the periplasmic domain, the second transmembrane helix, and the linker domain of $\operatorname{VirA}_{\mathrm{C} 58}$ (residues 241 to 418) is sufficient to confer maize agroinfection competence on VirA $_{\mathrm{A} 6}$ in a pTiA6 background.

It is interesting to note that the VirA hybrids encoded on plasmids pJD128W, pJD131W, and pJD130W exhibited agroinfection frequencies below those conferred by either of the parent VirA molecules. These hybrids also showed reduced responsiveness in vir induction measurements (data not shown), suggesting that they are composed of interacting domain pairs less able to communicate with one another than the wild type.

In addition, these data suggest a role for the periplasmic domain of VirA in maize agroinfection. The periplasmic do- main of $\operatorname{Vir}_{\mathrm{C} 58}$ is able to partially restore maize agroinfection competence to $\operatorname{VirA}_{\mathrm{A} 6}(\mathrm{pJD} 113 \mathrm{~W})$, and the reverse hybrid (pJD105W) is reduced in maize agroinfection competence versus wild-type $\operatorname{Vir}_{\mathrm{C} 58}$. However, while it is clear that the periplasmic domain does play a role in determining the competence for maize agroinfection, the region composed of residues 241 to 418 harbors the major determining factor or factors.

The DNA segment of virA that encodes the major strainspecific determinant of maize agroinfection codes for a portion of the periplasmic domain, the second transmembrane helix, and the cytoplasmic linker domain (Parkinson and Kofoid 1992). Database searches with these segments of different VirA proteins did not reveal any statistically significant matches with other proteins, except for the VirA proteins of other Agrobacterium strains. Multiple alignment of the VirA proteins reveals that the agroinfection-determinant domain of VirA is highly conserved. We compared protein sequences from agroinfection-competent and agroinfectionimpaired strains in search of the amino acid changes that would discriminate between these two groups of strains. Twenty residues were found to be group specific (Fig. 2). These changes are concentrated at the end of the periplasmic domain and in the C-terminal half of the linker domain. Moreover, the impact of these substitutions might also be different. For example, of the four closely spaced, group-specific substitutions in the periplasmic domain (specifically, the tip of the periplasmic domain), three (K243E/A, Q251K/A, and $\mathrm{R} 254 \mathrm{E} / \mathrm{V})$ change the residue polarity and the fourth (S252N/R) significantly alters the size of the side chain. However, only three changes in the linker domain are associated with a group-specific difference in side chain polarity or size, and these substitutions are widely spaced. The variable patch of amino acids preceding the second transmembrane helix is a

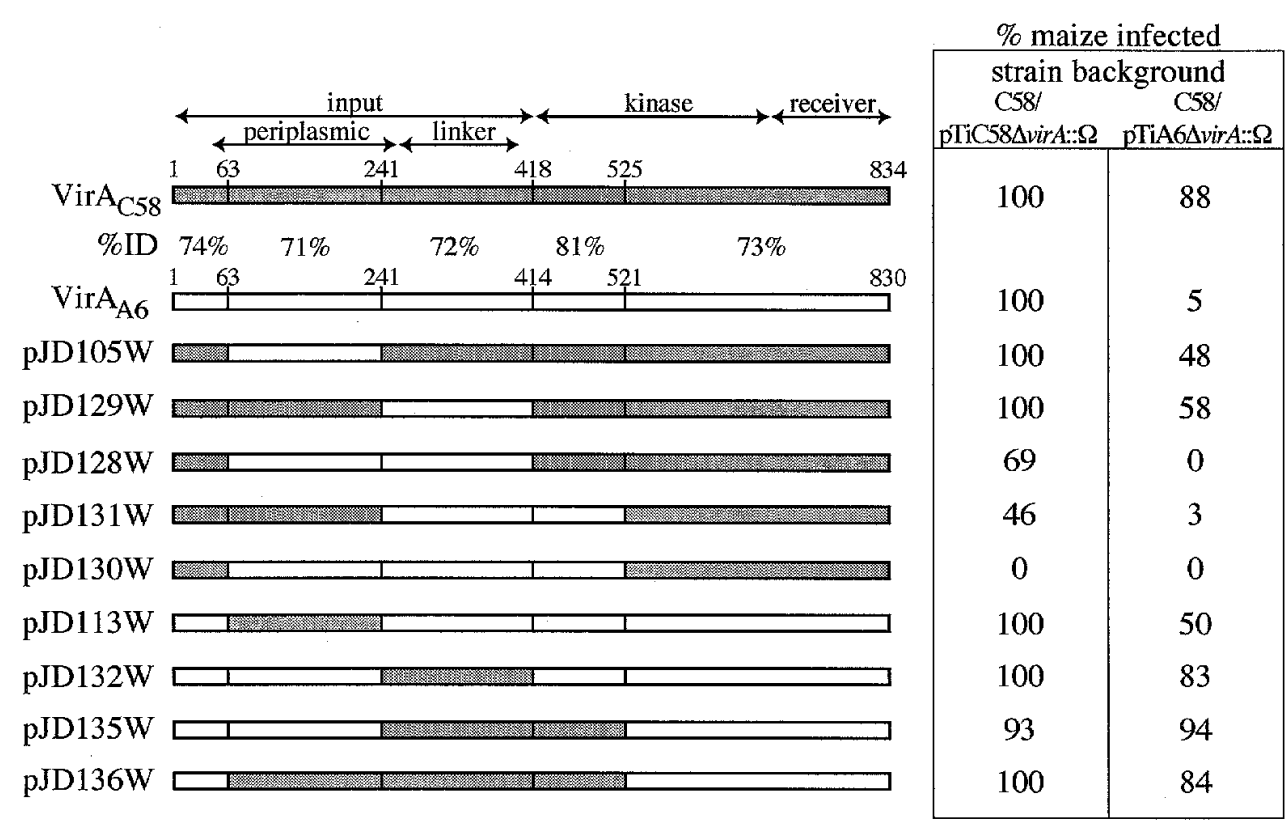

Fig. 1. Various VirA chimeras and corresponding maize agroinfection frequencies in two separate pTi plasmid backgrounds. The input (periplasmic and linker), kinase, and receiver domains are indicated by horizontal arrows above $\mathrm{VirA}_{\mathrm{C} 58}$. Residues derived from VirA $\mathrm{A}_{\mathrm{C} 8}$ are shaded. Residue number at chimeric fusion points is indicated above VirA $\mathrm{C}_{58}$ and $\mathrm{VirA}_{\mathrm{A} 6} . \% \mathrm{ID}=$ percentage of identity between peptide sequences of VirA $_{\mathrm{C} 58}$ and VirA $\mathrm{A}_{\mathrm{A}}$. Plasmid designations for the various chimeras are listed to the left of their respective schematic representations. 
plausible target for the further analysis of maize agroinfection capacity of VirA proteins.

Given the likely role of the linker domain in phenolic recognition (Chang and Winans 1992; Doty et al. 1996), these data imply that the ability of the sensor molecule VirA to recognize a particular inducing compound or compounds is key in determining which strains will infect maize. These data, in conjunction with the evidence presented above for a pTiA6encoded, VirA $\mathrm{A}_{\mathrm{A}}$-specific inhibitor, suggest that a region of VirA $_{\mathrm{A} 6}$ including the C-terminal end of the periplasmic domain, second transmembrane domain, and linker domain may interact with the inhibitor, blocking a crucial interaction with a maize-derived inducer. Therefore, the ability to agroinfect maize may be determined by the ability of VirA to escape inhibition and respond to a particular inducing environment.

\section{The chromosomally encoded sugar-binding protein ChvE is absolutely required for agroinfection of maize.}

It has long been recognized that monosaccharides play a significant role in potentiating the vir induction response to phenolic compounds (Cangelosi et al. 1990; Shimoda et al. 1990). Agrobacterium strains in which $c h v E$ is nonfunctional are defective in vir gene induction and exhibit a limited host range compared with wild-type strains (Garfinkel and Nester 1980; Huang et al. 1990). We tested the ability of a C58 strain harboring a Tn5 insertion in $c h v E$ to agroinfect maize. The agroinfection competence of this mutant strain is completely abolished (Table 1). Again, this result emphasizes the crucial role of vir induction in determining host range.

ChvE is known to interact directly with the periplasmic domain of VirA (Shimoda et al. 1993), potentiating the response of VirA to inducing phenolic compounds (Cangelosi et al. 1990). Additionally, a mutant derivative of $\mathrm{VirA}_{\mathrm{A} 6}$, in which the periplasmic domain is deleted, has been shown to exhibit the same reduced vir induction and host range as a chvE mutant (Cangelosi et al. 1990). We deleted various regions of the periplasmic domain of $\mathrm{VirA}_{\mathrm{C} 58}$ in an attempt to disrupt the VirA-ChvE interaction and tested those deletion derivatives for their ability to agroinfect maize. Figure 3 illustrates the various deletion derivatives and their corresponding maize agroinfection frequencies.

The deletion derivative encoded by pJD108W deletes the Cterminal half of the $\operatorname{VirA}_{\mathrm{C} 58}$ periplasmic domain (residues 173 to 240). This derivative mimics a C58 $c h v E$ mutant strain in dicot host range, vir induction (data not shown), and maize agroinfection (Table 1 and Fig. 3). Surprisingly, unlike the identical $\mathrm{VirA}_{\mathrm{A} 6}$ periplasmic deletion (see above), the $\mathrm{VirA}_{\mathrm{C} 58}$ deletion derivative encoded by pJD104W does not exhibit the host range or vir induction limitations seen in the $c h v E$ mutant derivative of C58 (data not shown). In fact, pJD104W bypasses the requirement for ChvE for vir induction (Doty et al. 1996) and maize agroinfection (Fig. 3). The VirA $\mathrm{C}_{\mathrm{C} 58}$ periplasmic deletion derivative encoded by pJD103W is missing residues 63 to 172 of the periplasmic domain. This derivative exhibits vir induction and host range properties intermediate between those of wild-type $\operatorname{VirA}_{\mathrm{C} 58}$ and pJD108W (data not shown and Fig. 3).

These results are consistent with previously published hypotheses that the periplasmic region of VirA may harbor a repressive function that is modulated by the binding of ChvE::monosaccharide (Banta et al. 1994; Cangelosi et al. 1990; Heath et al. 1995; Shimoda et al. 1990; Turk et al. 1993). The repressive function may be distributed through the periplasmic region and exert its effect in the absence of ChvE::monosaccharide. The majority of the repressive function appears to be concentrated in the N-terminal half of the periplasmic domain, since the $\operatorname{Vir}_{\mathrm{C} 58}$ derivative encoded by pJD108W behaves as if it cannot respond to ChvE::monosaccharide to release the repression. However, when the $\mathrm{N}$ terminal half of the periplasmic region is also deleted (pJD104W), the repressive effect of the periplasmic region is completely released, allowing vir induction and host infection in the absence of ChvE. The intermediate vir induction and host range phenotype of the $\operatorname{Vir}_{\mathrm{C} 58}$ deletion derivative encoded by pJD103W indicates that the C-terminal half of the periplasmic domain also contributes, albeit in a minor role, to the repressive function of the periplasmic domain.

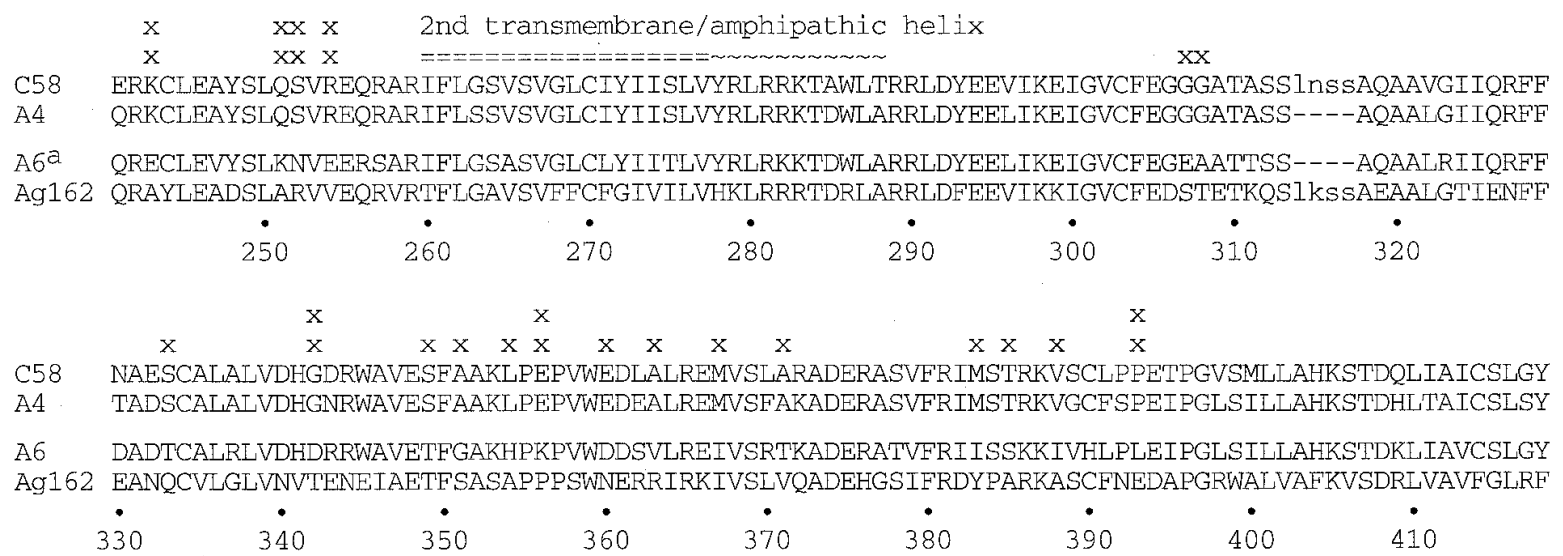

Fig. 2. Comparison of residues 241 to 418 of VirA proteins from strains competent for maize agroinfection (C58 and A4) with those not able to agroinfect maize $(\mathrm{A} 6$ and $\mathrm{Ag} 162)$. X (single or double) = group-specific conserved residues; XX = those residues that are significantly altered between the agroinfection-competent and agroinfection-incompetent strains; $====$ the second transmembrane domain (residues 260 to 280); and $\sim \sim ~=$ the amphipathic helix region (residues 278 to 288). The linker domain is represented by residues 278 to $418 . \mathrm{A}^{\mathrm{a}}=$ the sequence of VirA $\mathrm{A}_{15955}$ is identical to that of $\operatorname{VirA}_{\mathrm{A} 6}$ in this region. 


\section{Implications for Agrobacterium-mediated transformation of recalcitrant plants.}

The bacterial factors demonstrated to be important in determining maize agroinfecting ability are all concerned with sensing environmental conditions favorable for vir gene induction. Raineri et al. (1993) reported that a virA clone from a C58 Ti plasmid was sufficient to confer maize agroinfection ability on a nonagroinfecting strain. Additionally, they showed that a mutant $\mathrm{Vir}_{\mathrm{A} 6}$ derivative that induces vir gene expression in the absence of signal molecules can restore agroinfection ability to a nonagroinfecting strain. These data implicate a step upstream of VirG activation by VirA as the limiting step in determining the ability of particular strains to agroinfect maize. The steps upstream of VirG activation by VirA are those involving signal recognition by VirA. Since perturbation of the $c h v E$ locus eliminates monosaccharide-mediated enhancement of vir gene induction and also severely limits host

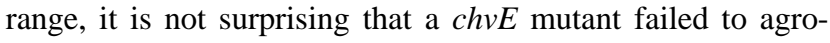
infect maize.

While Agrobacterium strains have proved to be invaluable tools in the genetic manipulation of many plants, several economically important members of Graminae cannot be routinely transformed. This study underscores the importance of signal recognition by the vir gene-induction machinery in the transformation of recalcitrant crop plants. Cells from various plants likely produce a signature complement of vir gene inducers and inhibitors in response to wounding. Additionally, a strain of Agrobacterium that is very efficient in transforming one plant will not necessarily be effective when used to transform a different species or cultivar of the same species. Therefore, it becomes important to ascertain the effectiveness of various strains in Agrobacterium-mediated transformation for each plant species.

While mutant derivatives of Agrobacterium that constitutively express vir genes may be useful in many cases with plants that are difficult to transform, these constitutive strains express their vir genes at a level lower than that of fully induced wild-type strains (Ankenbauer et al. 1991; McLean et al. 1994; Pazour et al. 1991). In fact, in the presence of the pTi plasmid, constitutive mutants of virA exhibit severely reduced constitutive vir expression (Pazour et al. 1991; J. D. Heath and E. W. Nester, unpublished data). Additionally, the exper- ience of this laboratory is that the constitutive $\operatorname{vir} G_{\mathrm{N} 54 \mathrm{D}}$ is unstable and reverts at a high frequency (D. M. Raineri, K. M. Stephens, and E. W. Nester, unpublished data). However, other groups have not observed this instability and have shown that constitutive $\mathrm{VirG}_{\mathrm{N} 54 \mathrm{D}}$ can increase T-DNA transfer to maize (Hansen et al. 1994). Nevertheless, vir-constitutive strains may not always work as well as wild-type strains or recombinant strains with novel chromosome-pTi combinations. For example, the so-called super-vir strain A281 is composed of the $\mathrm{Ti}$ plasmid from strain Bo542 and the chromosome of C58 (Hood et al. 1986; Jin et al. 1987). A281 is more virulent and has a broader host range than either parent strain. It is clear that a single bacterial vector will not work in every case, and investigators must be ready to employ a variety of Agrobacterium strains in difficult transformation situations.

\section{MATERIALS AND METHODS}

\section{Bacterial strains and plasmids.}

Strains used in this study are listed in Table 1. Genetic manipulation and growth of Agrobacterium strains were essentially as described (Cangelosi et al. 1991) except where noted. Strain At11068 was constructed by replacing the $4.4-\mathrm{kb}$ $K p n I$ fragment of A348 pTiA6 containing virA with the omega fragment. The omega fragment consists of the spectinomycin and streptomycin resistance gene, aadA, flanked by short, inverted repeats containing transcriptional and translational termination signals (Prentki and Krisch 1984). Specifically, a 7.5-kb HpaI fragment from the cosmid pVK219 (Knauf and Nester 1982) was cloned into the SmaI site on pUC9 (Vieira and Messing 1982), creating pTC284. pTC284 was digested with $K p n I$, releasing a 4.4-kb fragment harboring the virA locus. The remaining large fragment of pTC284 was treated with the T4 DNA polymerase to create blunt ends. A SmaI fragment containing the omega cassette $(\Omega)$ was ligated with the blunt end KpnI fragment of pTC284, resulting in the plasmid pTC291. pTC291 was cleaved with EcoRI, filled in with Klenow, and ligated with BamHI-cleaved, Klenowtreated pMH1801 (which carries the $s a c B$ gene) (Hynes et al. 1989), resulting in pTC299. pTC299 was introduced into strain A348 by electroporation, streak purified once, and then

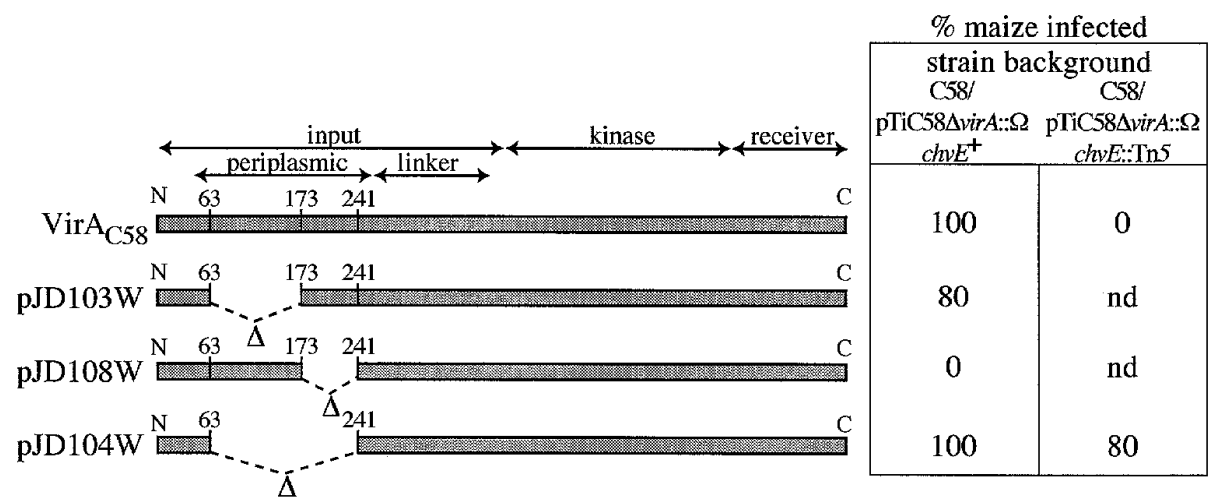

Fig. 3. Various $\operatorname{VirA}_{\mathrm{C} 58}$ periplasmic domain deletion derivatives and corresponding maize agroinfection frequencies in either a $c h v E^{+}$or $c h v E:: T n 5$ background. The input (periplasmic and linker), kinase, and receiver domains are indicated. Plasmid pJD103W encodes a VirA $\mathrm{C}_{58}$ derivative with an inframe deletion of residues 63 to 172; pJD108W encodes an in-frame deletion of residues 173 to 240; and pJD104W encodes an in-frame deletion of residues 63 to 240 . 
streaked out on AB glucose (Cangelosi et al. 1991), 5\% sucrose and $100 \mu \mathrm{g}$ of spectinomycin per milliliter, to select for double crossover and loss of the vector sequences. The relocation of the $\Delta v i r A:: \Omega$ recombinant locus onto the pTiA6 plasmid was confirmed by Southern hybridization and phenotypic assays (virulence). Thus, At11068 contains a precise deletion of the 4.4-kb KpnI fragment.

Plasmids pJD104 and pJD110, harboring identical deletion derivatives of $v i r A_{\mathrm{C} 58}$ and $\operatorname{vir} A_{\mathrm{A} 6}$, respectively, were constructed to aid in the assembly of the chimeric virA clones. A 5.6-kb fragment of pTiC58 harboring the virA gene was released by digestion with BamHI and HindIII and cloned into the pTZ19R cloning vector (United States Biochemical, Cleveland, $\mathrm{OH})$ resulting in plasmid pJD101. The virA gene encoded by pJD101 has two PstI sites, at positions 184 and 514, within the region encoding the periplasmic domain. Plasmid pJD103 was created by digesting pJD101 with PstI, releasing a 330-bp fragment. The vector was religated, resulting in a deletion derivative of vir $A_{\mathrm{C} 58}$ encoding an in-frame deletion of 110 amino acids of the periplasmic domain (residues 63 to 172). A new PstI site corresponding to the PstI site at position 718 of the $\operatorname{vir} A_{\mathrm{A} 6}$ coding sequence was introduced at position 718 of the $v i r A_{\mathrm{C} 58}$ coding sequence in clone pJD101 by PCR (polymerase chain reaction), resulting in a single amino acid change of a glutamic acid to the corresponding $\operatorname{VirA}_{\mathrm{A} 6}$ residue glutamine at amino acid 241. The alteration was confirmed by sequence analysis, and the resultant plasmid was designated pJD102. When pJD102 is digested with PstI, two small fragments (330 and 204 bp) are released corresponding to the $\mathrm{N}$ - terminal and $\mathrm{C}$-terminal halves, respectively, of the periplasmic domain-encoding region of virA $A_{\mathrm{C} 58}$. The native PstI site at position 514 of the virA $A_{\mathrm{C} 58}$-coding sequence in clone pJD102 was destroyed by PCR with no resulting residue changes. This plasmid was designated pJD111. Plasmid pJD104 was created by digesting plasmid pJD111 with PstI, releasing a 534-bp fragment. The vector was religated, resulting in a deletion derivative of $v_{i r} A_{\mathrm{C} 58}$ encoding an in-frame deletion of 178 residues of the periplasmic domain. Plasmid pJD108 was created by digesting pJD104 with PstI and reintroducing the 330-bp Pst I fragment encoding the $\mathrm{N}$-terminal half of the periplasmic domain. Orientation was confirmed by restriction analysis. pJD110, the deletion derivative of virA $A_{\mathrm{A} 6}$ corresponding to pJD104, was made as follows. pIB400 (Cangelosi et al. 1990) harbors a clone of $v i r A_{\mathrm{A} 6}$ with the same sequences deleted as described for pJD104. pIB400 was digested with the restriction enzyme $A f l I I I$, releasing a $2.7-\mathrm{kb}$ fragment whose ends were subsequently filled in by the Klenow fragment of the DNA polymerase holoenzyme. pUC7 (Vieira and Messing 1982) was digested with BamHI, and the ends were filled in by the action of the Klenow fragment. The 2.7-kb fragment from pIB400 and the BamHI-digested pUC7 were ligated together, resulting in plasmid pJD110. Orientation was determined by restriction analysis.

pJD134, containing the wild-type virA $\operatorname{Ar}_{\mathrm{A}}$ sequence, was constructed by digesting pJD110 and a plasmid containing the complete virA $_{\mathrm{A} 6}$ sequence, pSW169 (Winans et al. 1989), with the restriction enzyme PstI. Pst I-linearized pJD110 and a 534bp fragment released from pSW169 upon PstI digestion were ligated together by the action of T4 DNA ligase to create plasmid pJD134. Correct orientation of the 534-bp fragment was confirmed by restriction analysis in this and all cases. Plasmid pJD105 was created by ligating together PstI-linearized pJD104 and the 534-bp PstI fragment from pSW169. The reciprocal hybrid, pJD113, was constructed by ligating together PstI-linearized pJD110 and the 534-bp PstI fragment from pJD111. Plasmids pJD128 and pJD129 were constructed in the following way. First, pJD104 and pJD110 were digested with PstI and BstEII. Second, the 519-bp PstI-BstEII fragment from pJD110 was ligated with the 657-bp and 6.7-kb Pst I$B s t$ EII fragments from pJD104. Since the BstEII sites on pJD104 have different overhangs, the triple ligation can proceed via only one pathway. The resulting plasmid, pJD124, was digested with PstI, and the 534-bp Pst I fragments from pSW169 and pJD111 were ligated with linearized pJD124 to create plasmids pJD128 and pJD129, respectively. Plasmid pJD132 is the reciprocal of pJD129 and was constructed just as pJD129, exchanging pJD104- and pJD111-derived fragments for pJD110- and pSW169-derived fragments, respectively. Plasmids pJD130 and pJD131 were constructed as follows: pJD104 and pJD110 were digested with PstI and $B g l \mathrm{II}$. The 841-bp PstI-BglII fragment from pJD110 was ligated with the 7.1-kb PstI-BglII fragment from pJD104, creating plasmid pJD125. pJD125 was linearized with PstI, and the 534-bp PstI fragments from pSW169 and pJD111 were ligated to the linearized pJD125, resulting in plasmids pJD130 and pJD131, respectively. Plasmids pJD135 and pJD136 are the reciprocals of pJD130 and pJD131 and were constructed in the same way, exchanging pJD104- and pJD111-derived fragments for pJD110- and pSW169-derived fragments and vice versa.

Each of the above virA hybrids and deletion derivatives was moved into a broad host range vector to allow plasmid maintenance in A. tumefaciens. The virA constructs on plasmids pJD102, pJD103, pJD104, pJD105, pJD108, pJD111, pJD128, pJD129, pJD130, and pJD131 were moved into pDMD2 (Raineri et al. 1993), a derivative of the IncW replicon pUCD2. Each virA-containing plasmid was digested with BamHI and HindIII, and the large, 5.6-kb fragment was isolated. The IncW plasmid pDMD2 was digested with BamHI and HindIII, and the large fragment was isolated. Each of the virA-containing 5.6-kb BamHI-HindIII fragments was ligated with the large BamHI-HindIII fragment from pDMD2. The virA constructs on plasmids pJD110, pJD113, pJD132, pJD134, pJD135, and pJD136 were moved into pDMD2 by digesting each virA-containing plasmid and pDMD2 with $B a m \mathrm{HI}$. The 3.3-kb, virA-containing BamHI fragments were isolated and ligated to the large $B a m \mathrm{HI}$ fragment from pDMD2. All of the resultant IncW plasmids were named by adding "W" to the end of the original virA plasmid name. For example, pJD105 became pJD105W.

The maize streak virus (MSV) binary vector pMSV-Ns(G) is an IncP vector conferring gentamycin resistance and harboring an MSV dimer between T-DNA border sequences (Raineri et al. 1993).

\section{Plant growth and inoculation conditions.}

Growth of Zea mays L. (extra early and eight-row) and preparation of bacterial inocula were essentially as described (Boulton et al. 1989). Except where noted, bacterial strains were not preinduced and were used at an inoculum density of $10^{8}$ colony-forming units per plant. Plants were examined for 
symptoms from 5 days postinoculation (dpi); those showing no symptoms 28 dpi were scored as uninfected. Typically, MSV symptoms are long, chlorotic streaks, abundant on leaves, that emerge 6 to 9 dpi (Boulton et al. 1991).

\section{ACKNOWLEDGMENTS}

This work was supported by grants GM32618(NIH) and DMB8704292(NSF) to E. W. Nester and National Institutes of Health fellowship GM15097 to J. D. Heath. MSV was held and manipulated at the John Innes Centre under MAFF license PHF1419B/1493/45; the John Innes Centre is aided by grants from the Biotechnology and Biological Sciences Research Council.

\section{LITERATURE CITED}

Ankenbauer, R. G., Best, E. A., Palanca, C. A., and Nester, E. W. 1991. Mutants of the Agrobacterium tumefaciens virA gene exhibiting acetosyringone-independent expression of the vir regulon. Mol. PlantMicrobe Interact. 4:400-406.

Banta, L. M., Joerger, R. D., Howitz, V. R., Campbell, A. M., and Binns, A. N. 1994. Glu-225 outside the predicted ChvE binding site in VirA is crucial for sugar enhancement of acetosyringone perception by Agrobacterium tumefaciens. J. Bacteriol. 176:3242-3249.

Boulton, M. I., Buchholz, W. G., Marks, M. S., Markham, P. G., and Davies, J. W. 1989. Specificity of Agrobacterium-mediated delivery of maize streak virus DNA to members of the Graminae. Plant Mol. Biol. 12:31-40.

Boulton, M. I., King, D. I., Donson, J., and Davies, J. W. 1991. Point substitution in a promoter-like region and the V1 gene affect the host range and symptoms of maize streak virus. Virology 183:114-121.

Cangelosi, G. A., Ankenbauer, R. G., and Nester, E. W. 1990. Sugars induce the Agrobacterium virulence genes through a periplasmic binding protein and a transmembrane signal protein. Proc. Natl. Acad. Sci. USA 87:6708-6712.

Cangelosi, G. A., Best, E. A., Martinetti, G., and Nester, E. W. 1991 Genetic analysis of Agrobacterium. Methods Enzymol. 204:384-397.

Chang, C.-H., and Winans, S. C. 1992. Functional roles assigned to the periplasmic, linker, and receiver domains of the Agrobacterium tumefaciens VirA protein. J. Bacteriol. 174:7033-7039.

Chilton, M.-D. 1993. Agrobacterium gene transfer: Progress on a "poor man's vector" for maize. Proc. Natl. Acad. Sci. USA 90:3119-3120.

Doty, S. L., Yu, M. C., Lundin, J. I., Heath, J. D., and Nester, E. W. 1996. Mutational analysis of the input domain of the VirA protein of Agrobacterium tumefaciens. J. Bacteriol. 178:961-970.

Garfinkel, D. J., and Nester, E. W. 1980. Agrobacterium tumefaciens mutants affected in crown gall tumorigenesis and octopine catabolism. J. Bacteriol. 144:732-743.

Grimsley, N., Hohn, B., Hohn, T., and Walden, R. 1986. "Agroinfection", an alternative route for viral infection of plants by using the Tiplasmid. Proc. Natl. Acad. Sci. USA 83:3282-3286.

Grimsley, N., Hohn, T., Davies, J., and Hohn, B. 1987. Agrobacteriummediated delivery of infectious maize streak virus into maize plants. Nature 325:177-179.

Hamilton, R. H., and Fall, M. Z. 1971. The loss of the tumor initiating ability in Agrobacterium tumefaciens by incubation at high temperature. Experientia 27:229-230.

Hansen, G., Das, A., and Chilton, M.-D. 1994. Constitutive expression of the virulence genes improves the efficiency of plant transformation by Agrobacterium. Proc. Natl. Acad. Sci. USA 91:7603-7607.

Heath, J. D., Charles, T. C., and Nester, E. W. 1995. Ti plasmid and chromosomally encoded two-component systems important in plant cell transformation by Agrobacterium. Pages 367-385 in: Two-Component
Signal Transduction. J. A. Hoch and T. J. Silhavy., eds. American Society for Microbiology, Washington, DC.

Hiei, Y., Ohta, S., Komari, T., and Kumashiro, T. 1994. Efficient transformation of rice (Oryza sativa L.) mediated by Agrobacterium and sequence analysis of the boundaries of the T-DNA. Plant J. 6:271-282.

Hood, E. E., Helmer, G. L., Fraley, R. T., and Chilton, M. D. 1986. The hypervirulence of Agrobacterium tumefaciens A281 is encoded in a region of pTiBo542 outside of T-DNA. J. Bacteriol. 168:1291-1301.

Hooykaas, P. J. J., and Beijersbergen, A. G. M. 1994. The virulence system of Agrobacterium tumefaciens. Annu. Rev. Phytopathol. $32: 157-179$.

Huang, M. L., Cangelosi, G. A., Halperin, W., and Nester, E. W. 1990. A chromosomal Agrobacterium tumefaciens gene required for effective plant signal transduction. J. Bacteriol. 172:1814-1822.

Hynes, M. F., Quandt, J., O’Connell, M. P., and Puhler, A. 1989. Direct selection for curing and deletion of Rhizobium plasmids using transposons carrying the Bacillus subtilis sacB gene. Gene 78:111-120.

Ishida, Y., Saito, H., Ohta, S., Hiei, Y., Komari, T., and Kumashiro, T. 1996. High efficiency transformation of maize (Zea mays L.) mediated by Agrobacterium tumefaciens. Nat. Biotech. 14:745-750.

Jin, S. G., Komari, T., Gordon, M. P., and Nester, E. W. 1987. Genes responsible for the supervirulence phenotype of Agrobacterium tumefaciens A281. J. Bacteriol. 169:4417-4425.

Kado, C. 1991. Molecular mechanisms of crown gall tumorigenesis. Crit. Rev. Plant Sci. 101:1-32.

Knauf, V. C., and Nester, E. W. 1982. Wide host range cloning vectors: A cosmid clone bank of an Agrobacterium Ti plasmid. Plasmid 8:45-54.

Lee, Y.-W., Jin, S., Sim, W.-S., and Nester, E. W. 1995. Genetic evidence for direct sensing of phenolic compounds by the VirA protein of Agrobacterium tumefaciens. Proc. Natl. Acad. Sci. USA 92:12245-12249.

McLean, B. G., Greene, E. A., and Zambryski, P. 1994. Mutants of Agrobacterium VirA that activate vir gene expression in the absence of the inducer acetosyringone. J. Biol. Chem. 269:2645-2651.

Parkinson, J. S., and Kofoid, E. C. 1992. Communication modules in bacterial signaling proteins. Annu. Rev. Genet. 26:71-112.

Pazour, G. J., Ta, C. N., and Das, A. 1991. Mutants of Agrobacterium tumefaciens with elevated vir gene expression. Proc. Natl. Acad. Sci. USA 88:6941-6945.

Prentki, P., and Krisch, H. M. 1984. In vitro insertional mutagenesis with a selectable DNA fragment. Gene 29:303-313.

Raineri, D. M., Boulton, M. I., Davies, J. W., and Nester, E. W. 1993. VirA, the plant signal receptor, is responsible for the Ti plasmid-specific transfer of DNA to maize by Agrobacterium. Proc. Natl. Acad. Sci. USA 90:3549-3553.

Shimoda, N., Toyoda-Yamamoto, A., Nagamine, J., Usami, S., Katayama, M., Sakagami, Y., and Machida, Y. 1990. Control of expression of Agrobacterium vir genes by synergistic actions of phenolic signal molecules and monosaccharides. Proc. Natl. Acad. Sci. USA 87:66846688.

Shimoda, N., Toyoda-Yamamoto, A., Aoki, S., and Machida, Y. 1993. Genetic evidence for an interaction between the VirA sensor protein and the ChvE sugar-binding protein of Agrobacterium. J. Biol. Chem. 268:26552-26558.

Turk, S. C. H. J., van Lange, R. P., Sonneveld, E., and Hooykaas, P. J. J. 1993. The chimeric VirA-Tar receptor is locked into a highly responsive state. J. Bacteriol. 175:5706-5709.

Vieira, J., and Messing, J. 1982. The pUC plasmids, an M13mp7derived system for insertion mutagenesis and sequencing with synthetic universal primers. Gene 19:259-268.

Winans, S. C., Kerstetter, R. A., Ward, J. E., and Nester, E. W. 1989. A protein required for transcriptional regulation of Agrobacterium virulence genes spans the cytoplasmic membrane. J. Bacteriol. 171:16161622.

Zambryski, P. C. 1992. Chronicles from the Agrobacterium-plant cell DNA transfer story. Annu. Rev. Plant Physiol. 43:465-490. 